\title{
LETTERS
}

\section{Art at the McGill University Health Centre}

We write concerning the article titled "From Queen Victoria to Sausage Pants: art in the superhospital," by Drs. Tembeck and Hunter in the Jan. 8, 2018 issue of CMAJ. ${ }^{1}$ Although we regret the delay, the article has only recently come to our attention and, despite the time lag, demands a response.

The intention of the authors' piece was to critique the art collection at the McGill University Health Centre's Glen site, focusing primarily on the recently commissioned public art rather than on the impressive collection that inhabits our walls, courtesy of our donors. It is strange that they did not mention the RBC Art and Heritage Centre of the McGill University Health Centre, which is responsible for the collection. In fact, since 2013 we have been mandated to preserve the heritage of the hospitals that moved to the new Glen site: the Montreal Children's and Royal Victoria hospitals and the Montreal Chest Institute. We were in charge of collecting, storing and installing the art in their new home. The overall mission is to create a healing environment through critical curation, informed by a coordinating committee and an advisory committee; these are made up of a wide range of individuals representing various areas of the arts and the different hospitals of the McGill University Health Centre. It is clear to both committees that our constituents are the patients, the families and the employees. Their needs - whether distraction, relaxation or education - are an important consideration in our development of the healing environment.
As art is frequently offered to the hospital, an acquisition committee has been established to ensure quality. It has also established a direction for preferred works or acquisitions; contemporary photography will be the principal focus, but other media are included. With the help of the committees, there have already been 5 exhibits of contemporary photography or drawings. We aim to continue this practice of highlighting local contemporary artists with the objective of exposing viewers to artwork they would not normally have the chance to see, and pushing the boundaries of what is colloquially or academically acceptable within a hospital space.

The authors are largely critical of the public art. They fail to mention that the selection process was rigorously led by the Ministère de la Culture et des Communications. A specific committee for each artwork was made up of 3 artists, and an art historian, an architect and 3 staff from the McGill University Health Centre (usually individuals from the Art and Heritage Centre, an administrator with links to the new building, and another interested in the esthetics of where the work would be placed). The committee started with 32 proposals, trimmed to 8 , then 4 , and finally 1 was chosen. The contemporary nature of the art is evident and the pieces are all by working artists in Quebec, as directed by the Politique d'intégration des arts à l'architecture.

Regarding the 2 works the authors selected for discussion, Queen Victoria is part of our heritage and we would be remiss not to have her on display. The sculpture was one of the priority pieces identified by the Royal Victoria Hospital as integral to the institution and the community. The central corridor in which she has been positioned will eventually be filled with other paintings that reference the history of the institutions and their evolution. However, Sausage Pants was hung in a barren corridor with low traffic at the old Royal Victoria Hospital site, and while distracting, has not been requested to be rehung anywhere; it is hardly an "old friend."

We prioritize pieces that remain in the collective memory, represent the institution and reflect contemporary curation. To date, more than 500 works have found a new home. We are extremely fortunate to have been given the opportunity to plan and install pieces thoughtfully, so that when patients and families "encounter art in hospitals," it will change their experience in and understanding of the McGill University Health Centre and what a 21st-century hospital can be.

\section{Jonathan L. Meakins MD}

Director

\section{Alexandra Kirsh MA}

Curator

RBC Art and Heritage Centre of the McGill University Health Centre, Montréal, Que.

- Cite as: CMAJ 2018 December 10;190: E1457. doi: 10.1503/cmaj.70644

\section{Reference}

1. Tembeck T, Hunter M. From Queen Victoria to Sausage Pants: art in the superhospital. CMAJ 2018; 190:E18-20.

Competing interests: Jonathan Meakins and Alexandra Kirsh are employed by RBC Art and Heritage Centre of the McGill University Health Centre, Montréal, Que. 